\title{
O DISCURSO OFICIAL DE EDUCAÇÃO PARA O EXERCÍCIO DA CIDADANIA E O PAPEL DO ENSINO DE SOCIOLOGIA
}

\author{
Valci Melo \\ Universidade Federal de Alagoas - UFAL
}

\section{RESUMO}

O presente estudo analisa o discurso oficial acerca da "formação para o exercício da cidadania" e os sentidos atribuídos ao ensino da Sociologia neste processo. Para tal, investiga-se, à luz da Análise do Discurso filiada ao filósofo francês Michel Pêcheux (1938-1983), os "efeitos de sentidos" materializados em documentos como a Lei de Diretrizes e Bases da Educação Nacional (LDB 9.394/96), as Diretrizes Curriculares Nacionais para o Ensino Médio (DCNEM) de 1998 e de 2012, os Parâmetros Curriculares Nacionais para o Ensino Médio (PCNEM) de 1999 e as Orientações Curriculares para o Ensino Médio, Conhecimentos de Sociologia (OCEM-Sociologia) de 2006. Ao longo do estudo, demonstra-se a afinidade entre o discurso oficial de "preparação para o exercício da cidadania" - finalidade junto à qual o ensino de Sociologia é chamado a atuar - e a defesa da sociedade capitalista como a única alternativa societária viável. Por fim, conclui-se que o discurso oficial, ressalvadas as diferenças entre as materialidades discursivas analisadas, busca disciplinar o ensino de Sociologia e controlar suas possibilidades formativas de modo que não ultrapasse os limites da adaptação dos estudantes à ordem social vigente.

Palavras-chave: Documentos oficiais; Ensino de Sociologia; Cidadania; Educação Básica; Análise do Discurso.

\section{THE OFFICIAL DISCOURSE OF "EDUCATION FOR THE EXERCISE FOR CITIZENSHIP" AND THE ROLE OF TEACHING OF SOCIOLOGY}

\begin{abstract}
This study analyzes the official discourse about "education for the exercise of the citizenship" and the meanings attributed to the teaching of Sociology in this process. To do this, is investigated in the light of Discourse Analysis affiliated with the French philosopher Michel Pêcheux (1938-1983), the "effects of meanings" materialized in documents such as the Law of Guidelines and Bases of National Education (LDB 9.394 / 96), the National Curriculum Guidelines for High School (DCNEM) 1998 and 2012, the National Curriculum Parameters for the High School (PCNEM) of 1999 and the Curriculum Guidelines for High School, knowledges of Sociology (OCEM-Sociology) 2006. Throughout the study, we demonstrate the affinity between the official discourse of "education for citizenship" - purpose with which the teaching of Sociology is called to act and the defense of capitalist society as the only alternative viable of the society. Finally, it is concluded that the official discourse, except the differences between the analyzed discursives materialities, seeks disciplinary the teaching of Sociology and control their training possibilities so that does not exceed the limits of adaptation of students to the social order established.
\end{abstract}

Keywords: Official documents; Teaching of Sociology; Citizenship; Basic Education; Discourse Analysis. 


\section{Introdução}

É sabido que a palavra cidadania tem origem dupla, expressando na vertente grega o direito e a capacidade de participação direta nos destinos da coletividade e, na acepção latina, o vínculo de dependência jurídica entre o individuo e o Estado (CORTINA, 2005). Ambas as concepções são associadas e alargadas na modernidade, sobretudo, com o desenvolvimento do capitalismo e sua intrínseca necessidade de uma relação sóciocontratual entre indivíduos considerados naturalmente livres, iguais e proprietários. No entanto, como observa Tonet (2005, p. 74):

Considerados apenas neste aspecto abstrato de membros da sociedade civil, todos os homens são livres, iguais e proprietários. Mas o que significa exatamente isto? O que significa a liberdade para este homem "natural"? Significa o "direito" de buscar, por todos os meios ao seu alcance, a satisfação dos seus interesses, o que implica necessariamente o choque e a luta contra os outros indivíduos, movidos pela mesma lógica. [...] Por sua vez, a igualdade significa que todos os homens têm o mesmo "direito" de mover-se de acordo com esta lógica [...]. Enfim, a propriedade significa que todos eles dispõem de algum bem que pode ser de interesse para os outros, enquanto cada um tem carências para cuja satisfação deverá entrar no circuito da troca mercantil.

A partir desse contexto, graças à intensa luta dos trabalhadores (COUTINHO, 2008), a cidadania avançou de sua dimensão civil para a conquista popular de direitos políticos e sociais ${ }^{1}$. No entanto, a partir da década de 1970 ocorreu, a nível mundial, uma inflexão nesse movimento de conquistas sociais, com a crise do Estado de bem-estar social e a reestruturação produtiva, sendo a esfera da cidadania, contraditoriamente, bombardeada em sua dimensão social e, ao mesmo tempo, requisitada como forma de sociabilidade para além de sua acepção jurídico-política (CORTINA, 2005; TONET, 2007; MORAES, 2009).

Cortina (2005), lembra que na década de 1990 o conceito voltou à moda e justifica tal fato devido às mudanças societárias em desenvolvimento que, ao exacerbarem o individualismo no campo econômico, necessitam, por outro lado, criar um vínculo social de pertencimento e de identidade imprescindíveis à manutenção da ordem e da coesão social. Este vínculo, por sua vez, é dado a partir da ideia de cidadania, a qual, nesse novo cenário, além de corresponder a uma relação política que liga o indivíduo ao Estado, corresponde a um estilo de vida almejado.

No Brasil, desde meados dos anos 1970, o conceito está na ordem do dia e em disputa por diferentes concepções de sociedade (DAGNINO, 1994; TONET, 2005; MORAES, 2009). Nesse período, sob a forte repressão do governo militar e decepcionados com a experiência soviética, cujo maior defeito teria sido a falta de socialização do poder político, diversos movimentos e atores sociais gestam, no dizer de Dagnino (1994), uma "nova noção de cidadania", a partir da qual redirecionam sua luta, outrora até articulada com a construção do socialismo, para a necessária resistência imediata ao regime militar e à construção de uma sociedade democrático-cidadã (TONET, 2007).

$\mathrm{Na}$ esteira de Pêcheux (1995, p. 160-161), consideramos que as palavras, produzidas e veiculadas sob determinadas condições de produção discursiva ${ }^{2}$, não possuem um sentido fixo, literal, mas significam a partir da formação discursa ${ }^{3}$ de onde são enunciadas. No entanto, esse pressuposto não ignora o fato de que o uso indiscriminado dos mesmos termos e conceitos por formações discursivas antagônicas tem implicações 
sérias no processo de lutas de classes, no interior do qual a linguagem tem um papel imprescindível.

É, pois, conforme Dagnino (2004), isto que vem acontecendo intensamente na América Latina e, especialmente, no Brasil. Para a autora, a "confluência perversa" entre o projeto neoliberal, resultante da crise estrutural dos anos 1970, e o projeto democratizante, oriundo do enfrentamento dos regimes autoritários que marcaram os países latinoamericanos na segunda metade do século XX, resultou naquilo que ela denomina "crise discursiva", caracterizada, no caso brasileiro,

[...] pela disputa político-cultural entre esses dois projetos e pelos deslocamentos de sentido que ela opera em três noções - Sociedade Civil, Participação e Cidadania - que constituem as referências centrais para o entendimento dessa confluência (DAGNINO, 2004, p. 196).

De acordo com a autora, a perversidade desta confluência consiste "[...] no fato de que, apontando para direções opostas e até antagônicas, ambos os projetos requerem uma sociedade civil ativa e propositiva" (DAGNINO, 2004, p. 197). Isto é, utilizando no âmbito discursivo aquilo que a autora denomina de "referências aparentemente comuns", esses projetos antagônicos travam uma intensa luta de sentidos, provocando, conforme Dagnino (2004), uma "crise discursiva" que exige bastante atenção, sobretudo, no campo militante, uma vez que

[...] Nessa disputa, onde os deslizamentos semânticos, os deslocamentos de sentido, são as armas principais, o terreno da prática política se constitui num terreno minado, onde qualquer passo em falso nos leva ao campo adversário (DAGNINO, 2004, p. 198).

É no interior dessa disputa de sentidos, provocada pelo que a autora chama de "confluência perversa" entre projetos societários antagônicos que, conforme Dagnino (2004), se insere o conceito de cidadania na atualidade brasileira. Ou seja, depois de um processo de ressignificação pelo qual teria passado ao longo da década de 1980, quando, sob a liderança dos movimentos sociais em luta pela redemocratização e pela conquista e reinvenção permanente de vários tipos e níveis de direitos, foi posta para além da relação jurídico-política entre os indivíduos e o Estado (DAGNINO, 1994), a cidadania no contexto neoliberal teria sofrido uma inflexão provocada pelo ataque deste projeto à cultura política participativa, construída nos anos anteriores, substituindo o enfrentamento do Estado pela estratégia de parceria entre sociedade civil e esfera estatal (DAGNINO, 2004, p. 201).

Assim, com implicações diretas na reconfiguração de conceitos como sociedade civil, participação e cidadania, esta "confluência perversa", no que tange especificamente ao último conceito, provoca uma retomada e um aprofundamento da perspectiva liberal, reduzindo o significado desta categoria a uma dimensão individualista, moral e caridosa, cuja consequência, conforme Dagnino (2004, p. 212), é o "encolhimento das responsabilidades sociais do Estado" e a despolitização contínua da sociedade.

Embora concordemos com a autora acerca das implicações prático-políticas do uso indiscriminado dos conceitos com os quais lidamos cotidianamente, pensamos ser mais adequada a ideia de "tensão discursiva", uma vez que há apenas um conflito, uma contradição, uma ameaça de rompimento entre os projetos neoliberal e democratizante, e não, como faz crer o conceito de "crise discursiva", uma mudança substancial entre eles. 
É, pois, no bojo dessa disputa de sentidos do termo cidadania, e em virtude do triunfo da ideologia neoliberal, que a Lei de Diretrizes e Bases da Educação Nacional (Lei n. 9.394, de 20 de dezembro de 1996, doravante LDB 9.394/96) será elaborada e aprovada $^{4}$, bem como, serão produzidos os demais documentos ${ }^{5}$ dos quais recortamos as sequências discursivas a serem analisadas a seguir.

A investigação se deu a partir da Análise do Discurso de filiação marxista, considerando, como Cavalcante (2007, p. 10), que nesse tipo de análise “[...] interessa não o que uma palavra ou expressão significa, mas como funciona no discurso, na conjuntura histórica em que ela é enunciada".

\section{O discurso oficial de "preparação para o exercício da cidadania"}

Na letra da LDB 9.394/96, a defesa da cidadania aparece logo no artigo $2^{\circ}$, relacionada a uma das finalidades da educação básica:

[SD1 $]^{6}$ A educação, dever da família e do Estado, inspirada nos princípios de liberdade e nos ideais de solidariedade humana, tem por finalidade o pleno desenvolvimento do educando, seu preparo para o exercício da cidadania e sua qualificação para o trabalho (BRASIL, 1996, art. $2^{\circ}$, grifos nossos).

Considerando a discussão que introduz este estudo, cabe-nos questionar: o que a LDB entende por cidadão e qual o significado do exercício da cidadania por ela defendido? Com qual (is) outro(s) discurso(s) este dialoga? Quais os "efeitos de sentidos" (PÊCHEUX, 1995) produzidos no uso deste conceito pelo discurso oficial? Estas interrogações se fazem necessárias pelo fato de que, como observa Orlandi (2007, p. 30, grifos nossos):

Os dizeres não são [...] apenas mensagens a serem decodificadas. São efeitos de sentidos que são produzidos em condições determinadas e que estão de alguma forma presentes no modo como se diz, deixando vestígios que o analista de discurso tem de apreender. São pistas que ele aprende a seguir para compreender os sentidos aí produzidos, pondo em relação o dizer com sua exterioridade, suas condições de produção. Esses sentidos têm a ver com o que é dito ali mas também em outros lugares, assim como com o que não é dito, e com o que poderia ser dito e não foi. Desse modo, as margens do dizer, do texto, também fazem parte dele.

Assim, analisando a SD1, vemos que a educação, em consonância com as diretrizes da Declaração de Jomtien ${ }^{7}$, é considerada uma obrigação primeiramente da família e, só depois, do Estado. Isto, por sua vez, evidencia uma inflexão favorável às forças dominantes presentes no processo de elaboração da referida lei ${ }^{8}$, visto que aí registra-se uma recuada naquilo que já tinha sido duramente garantido no artigo 205 da Constituição Federal de 1988, a qual destaca o referido direito social como direito de todos e dever, primeiramente, do Estado (BRASIL, 1988, art. 205), vindo a família (instância privada) apenas de forma complementar. Ou seja, embora a LDB destaque, em seu artigo primeiro, que considera a educação como um processo para além da escolarização, incluindo-se aí, também, o que Libâneo (2007) chama de modalidades de educação informal e não formal, sua priorização da família como instância educadora no artigo $2^{\circ}$ entra em contradição com o que explicita no parágrafo $1^{\circ}$ do artigo primeiro, a saber: "Esta Lei disciplina a educação 
escolar, que se desenvolve, predominantemente, por meio do ensino, em instituições próprias" (BRASIL, 1996, art. $1^{\mathrm{o}}, \S 1^{\circ}$ ).

Por outro lado, diferentemente do que defendeu a Constituição Federal de 1988, no já referenciado artigo, a LDB 9.394/96 declara que a educação da qual trata é "inspirada nos princípios de liberdade e nos ideais de solidariedade humana". Ora, considerando, como Saviani (2008, p.199), que "[...] se trata de um documento legal que está em sintonia com a orientação política dominante hoje em dia e que vem sendo adotada pelo governo atual em termos gerais e, especialmente, no campo educacional", infere-se que tais princípios convocam sentidos da Formação Discursiva Liberal, na qual o individuo é livre enquanto possuidor/vendedor de sua força de trabalho e solidário nos limites da acirrada competição que o mesmo discurso busca dissimular, mas toma como inerente ao ser humano.

Orlandi (2007, p. 32), tratando acerca das implicações da memória discursiva (o lugar onde se encontra o já-dito) no intradiscurso (o dizer), mediante a ação do interdiscurso (movimento de articulação), destaca: "o fato de que há um já-dito que sustenta a possibilidade mesma de todo dizer, é fundamental para se compreender o funcionamento, a sua relação com os sujeitos e com a ideologia". Isto é, não sendo de uso privativo de cada um de nós, as palavras significam não conforme o nosso querer exclusivo, mas, principalmente, de acordo com as condições de produção que as condicionam e alicerçam, em estreita ligação com a história e com a ideologia, dimensões sobre as quais não temos nem controle nem consciência absoluta.

Para compreendermos melhor esta questão, vejamos a próxima sequência discursiva, recortada do documento anteriormente referido:

[SD2] Os conteúdos curriculares da Educação básica observarão, ainda, as seguintes diretrizes:

I - a difusão de valores fundamentais ao interesse social, aos direitos e deveres dos cidadãos, de respeito ao bem comum e à ordem democrática (BRASIL, 1996, art. 27, I, grifos nossos).

Ora, que valores são fundamentais ao interesse social em uma sociedade fragmentada em classes antagônicas? O bem será comum a quem nesse tipo de relações sociais? Parece-nos que a mesma sequência discursiva dá pistas importantes para a elucidação dos "efeitos de sentidos" (PÊCHEUX, 1995) aí produzidos, pois, mais adiante, ela acrescenta que os referidos valores devem auxiliar o exercício de direitos e deveres e o respeito à ordem democrática. Com isso, a SD2 tanto interdita a Formação Discursiva Revolucionária, cuja luta está comprometida com a construção de uma sociedade sem classes sociais, como também, aciona "efeitos de sentidos" da Formação Discursiva Liberal, defensora dos valores democrático-cidadãos como horizonte societário.

Tratando, a partir do filósofo francês Michel Foucault (1926-1984), acerca da interdição, Cavalcante (2007, p. 88-89) destaca que esta categoria consiste em uma manobra discursiva que busca controlar/bloquear o dizer divergente, impedindo a sua manifestação por este ir na contramação do que é dito e, assim, representar um perigo à ordem social vigente.

Assim, essa construção simbólica de um cidadão individual, acima dos interesses e conflitos de classes, capaz, ao mesmo tempo, de competir e se solidarizar com os demais, é representativa da tensão discursiva oriunda do que Dagnino (2004, p. 196) chama de "confluência perversa" no campo cultural entre projetos societários antagônicos. 
Diante dessas questões, infere-se que preparar para o exercício da cidadania (objetivo com o qual o ensino de Sociologia é solicitado a contribuir), no seio da LDB 9.394/96, é preparar para a adaptação à ordem social existente, como explicita a SD3:

[SD3] O ensino médio, etapa final da educação básica, com duração mínima de três anos, terá como finalidades:

$[\ldots]$

II - a preparação básica para o trabalho e a cidadania do educando, para continuar aprendendo, de modo a ser capaz de se adaptar com flexibilidade a novas condições de ocupação ou aperfeiçoamento posteriores (BRASIL, 1996, art. 35, grifo nosso).

Aqui, o sentido de "preparação para o exercício da cidadania" se mostra de forma clara: adaptação a um mundo em constante mudança e, especialmente, às condições de ocupação. Ora, conforme se pode ver textualmente na SD3, não cabe à educação formal instruir os estudantes para que questionem a ordem social vigente, o desemprego estrutural, a precarização do trabalho, entre outras mazelas que afetam diretamente suas vidas. Pelo contrário, cumprindo o que Mészáros (2008, p. 44) chama de internalização das demandas do capital, a escolarização - embora não apenas ela - busca induzir os estudantes ao conformismo, à autoculpabilização, na medida em que, sendo as coisas assim mesmo, caberia a eles aperfeiçoarem-se constantemente para poderem se adaptar a elas. Se, mesmo assim, não lograrem êxito, conforme reza a doutrina (neo)liberal com a qual tal discurso se identifica, a culpa não é do modelo de sociedade em vigor, e sim, dos indivíduos que não se esforçaram, ou no caso em discussão, não se aperfeiçoaram o suficiente. Assim, conforme nos ensina Mészáros (2008, p. 55, grifos do autor), a escolarização, controlada pelo Estado, é organizada de modo a "[...] agir como um cão de guarda ex-officio e autoritário para induzir um conformismo generalizado em determinados modos de internalização, de forma a subordiná-los às exigências da ordem estabelecida".

Também é importante destacar que, no bojo do referido documento, o discurso oficial cumpre a função de silenciar $^{9}$ o fato de que "[...] a política educacional vigente resulta do embate entre classes" (MELO, 2011, p. 162), isto é, silencia sobre os conflitos característicos de uma sociedade fragmentada em classes sociais, no interior da qual não há consenso sobre a finalidade educacional, e esta atividade não se constitui em instância neutra, mas articula-se com um dos projetos societários em disputa - predominante e frequentemente, com o projeto da classe dominante.

Seguindo a linha da LDB 9.394/96, as Diretrizes Curriculares Nacionais para o Ensino Médio (DCNEM de 1998), as quais se autodefinem como “[...] conjunto de definições doutrinárias sobre princípios, fundamentos e procedimentos a serem observados na organização pedagógica e curricular de cada unidade escolar" (BRASIL, 1998, art. $1^{\text {}}$ ), reafirmam a defesa do preparo para o exercício da cidadania e exigem que toda e qualquer atividade relacionada ao processo educativo esteja afinada com os "princípios estéticos, políticos e éticos" sobre os quais versa detalhadamente:

[SD4] I - a Estética da Sensibilidade, que deverá substituir a da repetição e padronização, estimulando a criatividade, o espírito inventivo, a curiosidade pelo inusitado, e a afetividade, bem como facilitar a constituição de identidades capazes de suportar a inquietação, conviver com o incerto e o imprevisível, acolher e conviver com a diversidade, valorizar a qualidade, a delicadeza, a sutileza, as 
formas lúdicas e alegóricas de conhecer o mundo e fazer do lazer, da sexualidade e da imaginação um exercício de liberdade responsável.

II - a Política da Igualdade, tendo como ponto de partida o reconhecimento dos direitos humanos e dos deveres e direitos da cidadania, visando à constituição de identidades que busquem e pratiquem a igualdade no acesso aos bens sociais e culturais, o respeito ao bem comum, o protagonismo e a responsabilidade no âmbito público e privado, o combate a todas as formas discriminatórias e o respeito aos princípios do Estado de Direito na forma do sistema federativo e do regime democrático e republicano.

III - a Ética da Identidade, buscando superar dicotomias entre o mundo da moral e o mundo da matéria, o público e o privado, para constituir identidades sensíveis e igualitárias no testemunho de valores de seu tempo, praticando um humanismo contemporâneo, pelo reconhecimento, respeito e acolhimento da identidade do outro e pela incorporação da solidariedade, da responsabilidade e da reciprocidade como orientadoras de seus atos na vida profissional, social, civil e pessoal (BRASIL, 1998, art. $3^{\circ}$, grifos nossos).

A extensa sequência discursiva justifica-se porque, sendo componente de um dos principais documentos regulamentadores da LDB 9.394/96, expressa as linhas operacionais que norteiam o cumprimento da referida Lei. Sua importância aqui também consiste no fato de que coube a este documento a interpretação de que a LDB 9.394/96, ao requisitar a Sociologia como um dos conhecimentos necessários ao exercício da cidadania, não estava definindo o ensino enquanto disciplina, mas sim, “[...] de maneira interdisciplinar pela área das Ciências Humanas e mesmo por outras disciplinas do currículo" (BRASIL, 2006, p. 103).

Indo além da "superfície linguística" das DCNEM de 1998, vemos que a SD4 alinha-se às análises já feitas acerca da LDB. Isto porque, como nos ensina Orlandi (2007, p. 66), a superfície linguística corresponde ao "corpus bruto", ao "dado empírico de um discurso concreto", fazendo-se necessário, no processo de análise, superar a dimensão linguística, ou seja, convertê-la "[...] em um objeto teórico, isto é, um objeto linguisticamente de-superficializado, produzido por uma primeira abordagem analítica que trata criticamente a impressão de 'realidade' do pensamento, ilusão que sobrepõe palavras, ideias e coisas".

Assim, observa-se que as DCNEM de 1998 explicitam, como em nenhum outro documento, o projeto de sociedade em torno do qual o discurso oficial está articulado. Ao mesmo tempo em que reconhecem a instabilidade dos tempos contemporâneos, as referidas diretrizes naturalizam ${ }^{10}$ a realidade social, considerando esta forma societária como a única alternativa possível, cabendo aos indivíduos não apenas se esforçarem para adaptarem-se (suportar, conviver, respeitar) ao mundo hodierno, mas também, militarem no "testemunho de valores de seu tempo, praticando um humanismo contemporâneo" e incorporando valores como "solidariedade", "responsabilidade" e "reciprocidade como orientadores de seus atos na vida profissional, social, civil e pessoal".

Como observa Cavalcante (2007, p. 90): “[...] o recurso à naturalização contém com frequência, também o processo de universalização a-histórica de determinadas características específicas da sociedade capitalista". Assim, nas DCNEM de 1998, encontra-se a síntese "perfeita" do que se entende por exercício da cidadania no seio do discurso oficial: a ação de indivíduos que pensam situarem-se acima dos interesses e conflitos de classe e são capazes, ao mesmo tempo, de competir e se solidarizar com os demais, sem que isto se constituía em uma contradição estrutural capaz de romper com a 
ordem vigente. E no caso particular das DCNEM de 1998, como observa Feijó (2012, p. 25), o referido documento

[...] parte do pressuposto de um mundo dado, a-histórico, de forma que restaria ao indivíduo melhorar sua situação, individualmente dentro desse contexto, levando-o a enxergar a realidade de uma forma conformada, buscando sempre o consenso ao invés do questionamento e da análise de diferentes aspectos.

Já no contexto dos governos petistas, são aprovadas novas Diretrizes Curriculares Nacionais para o Ensino Médio (DCNEM de 2012). Conforme Moehlecke (2012, p. 52), apesar das intensas críticas direcionadas às DCNEM de 1998, bem como, de novas diretrizes virem sendo propostas desde o governo Fernando Henrique Cardoso (FHC), somente no governo Dilma é que foi aprovada a Resolução CNE/CEB n ${ }^{\circ}$ 02, de 30 de janeiro de 2012, doravante DCNEM de 2012.

Estas, sendo resultado de vários eventos e iniciativas legais que se estenderam durante todo o governo Lula, com maior concentração no segundo mandato (2007-2010), a exemplo da universalização do ensino médio ${ }^{11}$ e da publicação das Diretrizes Curriculares Nacionais Gerais para a Educação Básica ${ }^{12}$, apresentam-se como um conjunto de

[SD5] [...] princípios, fundamentos e procedimentos, definidos pelo Conselho Nacional de Educação, para orientar as políticas públicas educacionais da União, dos Estados, do Distrito Federal e dos Municípios na elaboração, planejamento, implementação e avaliação das propostas curriculares das unidades escolares públicas e particulares que oferecem o Ensino Médio (BRASIL, 2012, art. $2^{\circ}$, grifo nosso).

Já aqui, como se pode ver textualmente, há uma atenuação do caráter impositivo presente nas DCNEM de 1998, as quais se autodefinem, como observamos anteriormente, como "conjunto de definições doutrinárias [...] a serem observados na organização pedagógica e curricular de cada unidade escolar" (BRASIL, 1998, art. $1^{\circ}$, grifos nossos). Isto é, embora Moehlecke (2012, p. 48-52) observe como uma das fragilidades das diretrizes de 1998 o reduzido poder de indução destas enquanto política curricular, seja por conta das implicações que sofreram no processo de recontextualização/acolhida escolar, seja por conta do caráter de política de governo destas; ou ainda em virtude da "[...] questão federativa e a liberdade de organização da educação atribuída aos estados e municípios" (MOEHLECKE, 2012, p. 51), não nos parece ser esta a compreensão das DCNEM de 1998 quando estas, além do já posto, exigem em seu artigo $3^{\circ}$ que toda e qualquer atividade relacionada ao processo educativo deve está afinada com os "princípios estéticos, políticos e éticos" definidos pelas referidas diretrizes como dignos de internalização.

No entanto, o que nos interessa mais aqui é apontar o que efetivamente tem de inovador nas DCNEM de 2012, especialmente no tocante ao ensino de Sociologia. E, neste aspecto, portanto, consideramos que a observação de Moehlecke (2012, p. 54) acerca da organização curricular nesse documento também é válida para outros pontos do mesmo, a saber:

Se, por um lado, as DCNEM-2011 13 não trazem novidades em relação à organização curricular do ensino médio, por outro é nítida a mudança na linguagem e nos referenciais teóricos presentes no documento aprovado, 
indicando uma sintonia entre o texto das novas diretrizes e as principais críticas realizadas às antigas diretrizes (MOEHLECKE, 2012, p. 54).

Neste particular, não somente concordamos com a autora, como também pensamos que a principal mudança entre as DCNEM de 1998 e as diretrizes de 2012 situa-se no campo da linguagem e no referencial teórico implicitamente utilizado e claramente ressignificado.

Para Florêncio et al. (2009), a ressignificação consiste na retomada de sentidos historicamente postos, mas não para simplesmente repeti-los, e sim, para a partir deles, produzir-se sentidos novos. E assim se dá porque, conforme os autores, ela acontece na articulação entre o intradiscurso (o dizer atual) e o interdiscurso (o já-dito), em um movimento que

Ao mesmo tempo em que aciona a memória, essa memória sofre alterações na medida em que ocorrem lacunas, falhas, apagamentos do que não pode e ou não deve ser dito. Sentidos historicamente sedimentados vêm à superfície pela via do esquecimento, pelo não-dito que, embora funcionem pela interdição, propiciam a produção de novos sentidos, num misto de memória e esquecimento, pelo movimento de idas e vindas entre as diferentes formações discursivas. Há, então, uma constante tensão entre lembrar e esquecer. Sujeitos não se constituem sem memória, da mesma forma que discursos não se produzern sem memória e sem inconsciente (FLORÊNCIO et al., 2009, p. 79).

Deste modo, mesmo incorporando alguns conceitos da tradição marxista, como o "reconhecimento" do trabalho enquanto mediação ontológica entre o homem e a natureza (art. $5^{\text {a }}$, inciso VIII, $\S 1^{\circ}$ ), a tecnologia como força produtiva (art. $5^{\circ}$, inciso VIII, $\S 3^{\circ}$, etc.), a historicidade e seletividade do conhecimento escolar (art. $6^{\circ}$, inciso V), observa-se que as DCNEM de 2012 não apenas silenciam acerca da origem teórica desses conceitos, como também, desloca-os para além de uma perspectiva de classe, categoria esta que não aparece no texto da Resolução que cria as DCNEM de 2012 e que se apresenta, no Parecer que versa sobre este documento, no bojo da discussão acerca da diversidade, dos direitos humanos e da inclusão social, conforme se vê adiante:

[SD6] Educar para os direitos humanos, como parte do direito à educação, significa fomentar processos que contribuam para a construção da cidadania, do conhecimento dos direitos fundamentais, do respeito à pluralidade e à diversidade de nacionalidade, etnia, gênero, classe social, cultura, crença religiosa, orientação sexual e opção política, ou qualquer outra diferença, combatendo e eliminando toda forma de discriminação (BRASIL, 2011, p. 23, grifos nossos).

Assim, embora o documento avance em alguns aspectos, como o reconhecimento da historicidade, da politicidade e da seletividade dos currículos escolares (BRASIL 2012, art. $5^{\circ}, \mathrm{V}$ e art. $6^{\circ}$ ), bem como, na defesa do trabalho enquanto princípio educativo e mediação "ontológica" no processo de transformação da natureza e produção da existência social (BRASIL 2012, art. 5', VIII, § $1^{\circ}$ ), não visualizamos nele um rompimento com a perspectiva de conformação e aperfeiçoamento da ordem social vigente, uma vez que coloca em pé de igualdade, como dignas do mesmo tratamento, questões que se referem à pluralidade e à diversidade (etnia, sexo, crença, etc.) com um elemento que constitui não uma questão de diferença, como quer fazer crer o documento, mas sim, uma questão de desigualdade (classe social). Ou seja, como observa Barros (2006), enquanto a diferença 
corresponde a uma categoria que diz respeito diretamente ao Ser (essencial), muitas vezes de caráter natural (sexo, tipo sanguíneo, etnia, etc.), como essências não iguais que se opõem, mas nem por isso, deixam de ser dignas do mesmo tratamento, a desigualdade situa-se no âmbito da valoração, do privilégio. Em outros termos: as diferenças enriquecem a vida social, constituem a diversidade humana e, enquanto tal, precisam ser reconhecidas e respeitadas. Já as desigualdades, a exemplo da fragmentação da sociedade em classes, são disparidades históricas que privilegiam alguns seres humanos em detrimento dos outros, carregando consigo forte carga de injustiça. Neste sentido, as desigualdades não devem ser tomadas como naturais e, portanto, insuperáveis, mas sim, precisam ser enfrentadas e erradicadas.

Neste aspecto, há uma sintonia entre as DCNEM de 2012 e as Diretrizes Curriculares Nacionais Gerais para a Educação Básica (BRASIL, 2010) quando, acerca da mesma questão, o Parecer CNE/CEB n $n^{\circ} 7 / 2010$, que versa sobre o referido documento destaca:

Para que a gestão escolar cumpra o papel que cabe à escola, os gestores devem proceder a uma revisão de sua organização administrativopedagógica, a partir do tipo de cidadão que se propõe formar, o que exige compromisso social com a redução das desigualdades entre o ponto de partida do estudante e o ponto de chegada a uma sociedade de classes (BRASIL, 2010, p. 53, grifos nossos).

É, pois, nesse contexto em que a sociedade de classes constitui-se não um obstáculo à emancipação humana ${ }^{14}$, mas sim, um ponto de chegada, um horizonte a ser alcançado; em que a fragmentação social em classes é vista como uma questão de diversidade, que se insere nas DCNEM a suposta conceituação do trabalho em sua dimensão ontológica e se defende, conforme se vê na sequência discursiva seguinte:

[SD7] integração entre educação e as dimensões do trabalho, da ciência, da tecnologia e da cultura como base da proposta e do desenvolvimento curricular (BRASIL, 2012, art. 5º, VIII).

Ora, neste aspecto, as DCNEM de 2012, diferentemente das diretrizes de 1998, buscam melhor camuflar o projeto societário em torno do qual se articulam, dissimulando, no hibridismo de seu discurso, o compromisso com a reprodução da ordem social vigente, ao retomarem discursos de uma formação discursiva com a qual não se identificam (a formação discursiva revolucionária). Assim, o referido documento faz uso do referencial teórico marxista, retirando deste algo que lhe é essencial: a crítica radical à sociedade de classes e a inviabilidade da emancipação humana sem a superação das classes sociais.

Nesse contexto, entende-se mais facilmente o porquê das DCNEM de 2012 buscarem responder às principais críticas direcionadas às DCNEM de 1998 (sobretudo no que tange ao referencial teórico) sem tecer maiores críticas aos princípios e finalidades da LDB 9.394/96, reconhecidamente construída e sancionada em estreita relação com a ideologia neoliberal (SAVIANI, 2008).

[SD8] As unidades escolares que ministram esta etapa da Educação Básica devem estruturar seus projetos político-pedagógicos considerando as finalidades previstas na Lei n ${ }^{\circ}$ 9.394/96 (Lei de Diretrizes e Bases da Educação Nacional):

$[\ldots]$ 
II - a preparação básica para o trabalho e a cidadania do educando para continuar aprendendo, de modo a ser capaz de se adaptar a novas condições de ocupação ou aperfeiçoamento posteriores (BRASIL, 2012, art. $4^{\circ}$, grifo nosso).

Como se vê na sequência discursiva $n^{\circ}$ 8, a LDB 9.394/96 é convocada pelas DCNEM de 2012 não somente por tratar-se de uma lei maior, cujos delineamentos devem ser considerados, mas pelo fato de que concorda-se com aquilo que é nela apregoado, a exemplo da vinculação entre o processo de escolarização e a necessidade de acomodação dos estudantes à ordem social vigente, às novas condições de ocupação, como se essa fosse a única alternativa histórica possível, conforme já enfatizamos ao analisar o mesmo discurso na SD3. Também destaque-se que o Parecer CNE/CEB n ${ }^{\circ}$ 5/2011 não tece quaisquer considerações acerca dos limites da LD 9.394/96, nem faz referência ao caráter neoliberal desta.

Assim, entendemos que a inovação na linguagem e no referencial teórico, longe de representar o que Oliveira $(2014$, p. 645) denomina de "ruptura" entre o documento de 1998 e as DCNEM de 2012, representa uma continuidade temática atualizada (PÊCHEUX, 1999), disfarçada de inovação, cuja expressão é a defesa da possibilidade de um mundo melhor no qual a fragmentação da sociedade em classes sociais seja tomada não como a raiz da desigualdade social a ser, no dizer do documento, reduzida (BRASIL, 2011, p. 23), mas como um componente do mundo plural e diverso que precisa ser respeitado e valorizado.

Nesse contexto, a transformação social preconizada pelo documento se dará mediante a prática daquilo que ele denomina de:

[SD9] [...] um humanismo contemporâneo expresso pelo reconhecimento, respeito e acolhimento da identidade do outro e pela incorporação da solidariedade (BRASIL, 2012, art. 16, V, grifo nosso).

Ou seja, como observa Paulo Netto (2010, p. 263), ao tratar das principais características da ideologia pós-moderna e das implicações de seu discurso pretensamente humanista e solidário:

[...] se à grande burguesia a crítica aberta à propriedade privada dos meios fundamentais de produção, a referência direta à exploração, o apelo à luta de classes e ao socialismo permanecem intoleráveis, não causam mossa as demandas de inclusão social, de combate às desigualdades, de requisições de cidadania e de solidariedade e de apelo a uma sociedade alternativa (PAULO NETTO, 2010, p. 263).

Já no que tange ao ensino de Sociologia, como observa Oliveira (2014, p. 647), o mérito das DCNEM de 2012 está em defender "[...] o fomento ao diálogo dentro e entre as áreas de conhecimento, mas sem o apagamento dos aspectos idiossincráticos de cada ciência". Isto é, mantendo a organização disciplinar por reconhecer ser preciso tratar da parte para se chegar ao todo, as DCNEM de 2012 garantem a permanência da Sociologia como componente curricular obrigatório no ensino de nível médio, o que, conforme o referido autor, não somente sinaliza positivamente acerca dos contornos que a ciência sociológica vem assumindo na Educação Básica, como também, exige desta, avanços no que tange à definição de um currículo nacional - além de abrir possibilidades para a renovação intelectual e "abrindo inclusive novas possibilidades de agendas de pesquisa em torno do Ensino de Sociologia na Educação Básica” (OLIVEIRA, 2014, p. 648). 
No que diz respeito ainda ao ensino de Sociologia, além do que já mencionamos acerca da LDB 9.394/96 e das DCNEM de 1998 e de 2012, dois outros documentos oficiais, ao abordarem o tema, embora com diferenças de enfoque que precisam ser consideradas, retomam e reafirmam a vinculação entre o ensino de Sociologia e a "preparação para o exercício da cidadania".

No primeiro caso, temos os Parâmetros Curriculares Nacionais para o Ensino Médio (PCNEM), da área de Ciências Humanas e suas Tecnologias, no interir da qual são contemplados conhecimentos de Sociologia, Antropologia e Ciência Política.

O documento foi elaborado logo após as DCNEM de 1998, ainda no governo FHC, e explicita que as ciências sociais surgiram como forma científica de explicação das transformações do mundo moderno, condição que também justifica o seu ensino na Educação Básica, visto que, contemporaneamente, passamos por mudanças, cujo poder analítico desta área do conhecimento é imprescindível.

No entanto, apesar de defender a relevância do ensino das Ciências Sociais, os PCNEM não avançam para além da interpretação das DCNEM de 1998, segundo a qual, como já vimos, o conhecimento sociológico deve ser dissolvido na área de Ciências Humanas e suas Tecnologias.

Quanto à problemática da cidadania, o documento retoma a LDB 9.394/96 e com ela se alinha ao defender que:

[SD10] [...] pela via do conhecimento sociológico sistematizado, o educando poderá construir uma postura mais reflexiva e crítica diante da complexidade do mundo moderno. Ao compreender melhor a dinâmica da sociedade em que vive, poderá perceber-se como elemento ativo, dotado de força política e capacidade de transformar e, até mesmo, viabilizar, através do exercício pleno de sua cidadania, mudanças estruturais que apontem para um modelo de sociedade mais justo e solidário (BRASIL, 1999, p. 37, grifos nossos).

Como se vê, defende-se que o conhecimento sociológico deve proporcionar tanto uma capacidade analítica, como também, uma "competência" interventora, sendo a cidadania, neste último caso, uma mediação no processo de construção do que o documento denomina de "modelo de sociedade mais justo e igualitário", o que, a nosso ver, explicita sua opção pelo aperfeiçoamento da ordem social vigente, e não, por sua radical superação, visto que pressupõe-se que esta ordem já contém justiça e igualdade, carecendo apenas intensificar tais qualidades. E isto se explicita, mais ainda, quando o mesmo documento, mais adiante, ao tratar das mudanças contemporâneas no mundo do trabalho e defender a insuficiência da teoria marxista no tratamento desta categoria, enfatiza:

[SD11] A análise do mercado de trabalho requer que se entenda o problema do desemprego estrutural, isto é, a diminuição constante e irreversível de cargos em empresas, enquanto uma realidade percebida, sobretudo, nos países industrializados da Europa (BRASIL, 1999, p. 37, grifos nossos).

No interior da SD11, o desemprego estrutural não deve ser apreendido enquanto construção histórico-social, resultante da reestruturação produtiva, operada como resposta à crise do Estado de bem-estar social. Pelo contrário, a análise de tal situação "requer que se entenda" (no sentido de aceitação) sua irreversibilidade, visto que tal fenômeno vem se dando nos principais países industrializados do Primeiro Mundo, acionando, assim, a 
memória discursiva ${ }^{15}$ presente na sabedoria popular, segundo a qual, "contra fatos não há argumentos".

Em 2006, final do primeiro mandato do governo Lula, é publicado o documento Orientações Curriculares para o Ensino Médio (OCEM), no interior do qual são contemplados os conhecimentos de Sociologia. Construído em diálogo intenso com o processo de reflexão coletiva e de luta dos educadores/cientistas sociais e de algumas de suas principais entidades profissionais e acadêmicas pelo retorno da disciplina Sociologia ao Ensino Médio (MORAES, 2011), as OCEM - Sociologia representam um avanço em relação aos documentos anteriores e um marco significativo na reconquista do ensino de Sociologia em nível médio, na medida em que argumenta em defesa do ensino do conhecimento sociológico via disciplina.

Em linhas gerais, o documento faz um histórico do ensino de Sociologia no Ensino Médio, questionando a interpretação, segundo a qual, a intermitência da disciplina teria relação com um caráter eminentemente crítico e revolucionário dela; defende o estranhamento e a desnaturalização como papel da Sociologia enquanto ciência na escola; preocupa-se com a transposição didática (relação entre a ciência de referência e a disciplina escolar); e defende o tratamento metodológico alicerçado no tripé teorias, conceitos e/ou temas.

Interpretando a finalidade "preparação para o exercício da cidadania", na LDB 9.394/96, como formação política, as OCEM - Sociologia questionam a relação entre o ensino desta disciplina e o exercício da cidadania, por entender que além de não se tratar de uma relação direta, também não é exclusiva do ensino dela. Apesar desta ressalva, destaca o documento:

[SD12] As razões pelas quais a Sociologia deve estar presente no currículo do ensino médio são diversas. A mais imediata, e de que já se falou, mas não parece suficiente, é sobre o papel que a disciplina desempenharia na formação do aluno e em sua preparação para o exercício da cidadania. Isso se tem mantido no registro do slogan ou clichê; quer-se ultrapassar esse nível discursivo e avançar para a concretização dessa expectativa (BRASIL, 2006, p. 109, itálico dos autores; negritos nossos).

Como é possível ver na SD12, o documento defende a "preparação para o exercício da cidadania", não somente, como uma das razões justificadoras da inserção da Sociologia no Ensino Médio, mas também, como "a mais imediata", argumentando em prol do avanço para "a concretização dessa expectativa".

No entanto, diferentemente dos documentos anteriores, as OCEM-Sociologia disfarçam melhor o tipo de projeto societário com o qual estão articuladas. Isto é, o referido documento evita, a todo o momento, assumir um posicionamento explícito, seja no tocante ao delineamento de um currículo nacional comum para a disciplina, seja no que se refere a uma perspectiva teórica ou a um projeto de sociedade.

Críticas nesta direção já foram empreendidas por estudos anteriores, a exemplo de Casão e Quinteiro (2007), como reconhece e rebate Amaury Cesar Moraes, coordenador da equipe do Ministério da Educação (MEC) responsável pela elaboração das OCEMSociologia.

Em artigo curiosamente intitulado Ciência e ideologia na prática dos professores de sociologia no ensino médio: da neutralidade impossível ao engajamento indesejável, ou seria o inverso?, Moraes (2014) rebate, entre outras críticas, aquelas que acusam as OCEM-Sociologia de flexibilizadoras por não apontarem um currículo nacional comum 
para o ensino de Sociologia, bem como, as que exigem do documento em tela um explícito posicionamento teórico e/ou societário.

Concordemos com o autor no rebate à primeira crítica, isto é, de que as OCEMSociologia não podem ser acusadas de flexibilizadoras, uma vez que, diferentemente de como as DCNEM de 1998 e os PCNEM de 1999 fizeram com as demais disciplinas, no caso da Sociologia, nunca existiu um currículo nacionalmente posto para ser flexibilizado. No entanto, discordamos dos argumentos de Moraes (2014) acerca do segundo grupo de críticas. Como o autor dá a entender, optou-se nas OCEM-Sociologia por um texto não engajado, não somente por se compreender ser mais benéfico ao debate acerca da inserção da Sociologia como disciplina junto aos órgãos oficiais de decisão (Conselho Nacional de Educação, Congresso Nacional, MEC e Presidência da República), mas também, porque, como reiteradas vezes destaca o Moraes, compreende-se não ser competência do Estado, nem do professor em sala de aula, tomar partido societário, uma vez que isto feriria o princípio da autonomia dos estudantes e constituiria um ato de irresponsabilidade Estatal e pedagógica.

Para referendar sua argumentação, Moraes (2014) recorre aos clássicos do pensamento sociológico, dando especial atenção aos postulados teóricos de Max Weber acerca da necessária responsabilidade social e pedagógica do professor e do cientista na formação das novas gerações, processo no qual, conforme Weber, deve-se evitar a mistura daquilo que é juízo de fato (e, portanto, objetivo, rigoroso e, no entender do autor, axiologicamente neutro), com o que situa-se no âmbito dos juízos de valor (ideológico, particular) (WEBER, 2001, p. 107-154).

Nada haveria a objetar se não estivéssemos inseridos em uma sociedade divida em classes sociais com interesses antagônicos, no interior da qual não existe neutralidade apesar de Moraes (2014) insistir que sua proposta está para além da defesa da neutralidade axiológica e do engajamento político-societário. Isto é, conforme o autor, o ensino de Sociologia terá mais condições de contribuir com a formação autônoma dos jovens, dandose a partir de um processo de alfabetização científica, como, segundo o mesmo, já ocorre nas Ciências Naturais.

Esta questão, portanto, merece destaque, pois corresponde à retomada, por Moraes (2014), de algo bastante comum, sobretudo, no processo de legitimação das Ciências Sociais, que é a tentativa de importação de modelos metodológicos e princípios epistemológicos das Ciências Naturais para o universo das Ciências Sociais. Esta postura de indistinção metodológica entre Ciências Naturais e Ciências Sociais, juntamente com a defesa implícita ou explícita de leis naturais que regem a vida social e, sobretudo, com a exigência de neutralidade axiológica, configuram, conforme observa Löwy (2000, p. 18), os alicerces da ciência positivista.

E aqui, esclareça-se, não estamos buscando identificar uma aproximação entre Moraes (2014) e a perspectiva positivista, simplesmente, por ele sugerir ao ensino de Sociologia a utilização de um recurso metodológico e de princípios epistemológicos do universo das Ciências Naturais, uma vez que tais campos científicos não são incomunicáveis. A questão central é que, ao fazer isso supondo criar uma "terceira via", como o autor mesmo denomina (MORAES, 2014, p. 32), uma alternativa entre o engajamento e a neutralidade axiológica, o autor nada mais faz do que retomar o velho dilema ciência versus ideologia, posicionando-se a favor de uma prática social alheia aos interesses e conflitos de classes, não somente no campo da ciência, mas também, no âmbito da prática pedagógica.

Assim, entendemos que o pensamento ${ }^{16}$ de Moraes (2014), enquanto coordenador e um dos principais autores das DCNEM-Sociologia, ajuda a esclarecer aquilo que a leitura 
isolada destas não nos possibilitaria: a opção teórica e societária do documento. E neste aspecto, pensamos que Souza (2012, p. 127, grifos do autor) tem razão quando, ao analisar as concepções pedagógicas presentes nos documentos oficiais, destaca que eles, inclusive, as OCEM-Sociologia,

[...] partem de uma matriz epistemológica comum. No caso dos PCN a preferência por Weber no repertório conceitual é clara. No caso dos demais documentos, o ponto de partida geral é o conceito de estranhamento e desnaturalização da realidade, que se fundamentam na concepção weberiana de "objetividade" e "neutralidade axiológica" do conhecimento nas Ciências Sociais.

Isto pode ser observado, no caso das OCEM-Sociologia, na centralidade que o documento concede aos conceitos de desnaturalização e estranhamento, ao colocá-los, seja como meio, seja como ponto de chegada do conhecimento sociológico em nível médio. Além disso, também pode ser inferido a partir do delineamento histórico e conceitual que o documento traça acerca da disciplina Sociologia no Ensino Médio, compreendendo-a como algo instrumental, no sentido não somente de poder ser usado para um lado ou para outro, mas principalmente, de poder ser ensinada sem compromisso direto com um projeto de sociedade.

A partir deste percurso, pensamos que, embora as OCEM-Sociologia busquem esconder sua opção societária, esta é possível de ser inferida, seja relacionando-as com os escritos posteriores de um dos seus principais autores, seja pela própria postura do documento: a pretensão de ser neutro no interior de uma sociedade fragmentada em classes sociais com interesses antagônicos, cujo conflito perpassa as mais variadas esferas da vida social, inclusive, a esfera da produção e da socialização do conhecimento sistematizado. Claro que, com isso, não pretendemos colocar no mesmo patamar um documento que, conforme observam as próprias OCEM-Sociologia, reveste-se de um caráter oficial (BRASIL, 2006, p. 131) e uma produção acadêmica que expressa as "opções pessoais ${ }^{17 \text { " }}$ de seu autor. No entanto, considerando o peso deste autor no processo de elaboração do referido documento, bem como, as aproximações e continuidades entre as duas produções - inclusive pelo fato de a segunda retomar, referendar e buscar rebater críticas feitas à primeira -, pensamos que o presente correlacionamento se faz, não apenas, viável, como também, necessário para uma melhor compreensão das OCEM-Sociologia.

\section{Considerações finais}

Neste trabalho, buscamos analisar os "efeitos de sentidos" (PÊCHEUX, 1995) produzidos por documentos oficiais do Estado brasileiro, ao relacionarem o ensino de Sociologia à "preparação dos estudantes para o exercício da cidadania".

Ao longo do estudo, que se deu à luz da Análise do Discurso, examinamos o corpus discursivo formado por sequências recortadas de documentos oficiais e mostramos que, ressalvadas as diferenças entre os documentos e os "efeitos de sentidos" por eles produzidos, no tocante ao que nos interessa neste estudo (a defesa da preparação dos estudantes para o exercício da cidadania e o papel da Sociologia), eles não apresentam diferenças substanciais, pois se a LDB 9.394/96, as DCNEM de 1998 e os PCNEM de 1999 se articulam em torno de um projeto societário declaradamente neoliberal, as OCEMSociologia e as DCNEM de 2012 também demonstram seu compromisso com o simples aperfeiçoamento da ordem social vigente, processo no qual "a preparação para o exercício 
da cidadania" terá um papel fundamental a cumprir - e a Sociologia é requerida justamente para com isso colaborar.

Assim, como observa Silva Sobrinho (2011), o discurso oficial, ao mesmo tempo em que reconhece a Sociologia enquanto componente curricular obrigatório do Ensino Médio brasileiro, busca discipliná-lo, controlá-lo, estabelecendo que os conhecimentos das Ciências Sociais (Antropologia, Política e Sociologia) necessários são aqueles que contribuem para formar o cidadão adaptado a um mundo social de historicidade seletiva, isto é, a uma sociedade que muda constantemente graças a ação humana, mas que não pode ir além das desigualdades sociais e da exploração do homem sobre o próprio homem.

\section{Referências}

ARAÚJO, Marta Maria de. Governo e sociedade na trajetória da nova LDB: dois projetos, duas versões, uma vontade política. Educação em Revista, Belo Horizonte, nº 30, dez. 1999.

BARROS, José D'Assunção. Igualdade, desigualdade e diferença: contribuições para uma abordagem semiótica das três noções. Revista de Ciências Humanas, Florianópolis, EDUFSC, n. 39, p. 199-218, abr. 2006.

BRASIL. Constituição da República Federativa do Brasil de 1988. Diário Oficial da União, Brasília, 05 de outubro de 1988.

Lei $\mathrm{n}^{\circ}$ 9.394, de 20 de dezembro de 1996. Estabelece as diretrizes e bases da educação nacional. Diário Oficial da União, Brasília, 23 de dezembro de 1996.

Resolução CEB no 3, de 26 de Junho de 1998. Institui as Diretrizes Curriculares Nacionais para o Ensino Médio. Diário Oficial da União, Brasília, DF, 5 ago. 1998.

Parâmetros Curriculares Nacionais Ensino Médio. Ciências Humanas e suas Tecnologias. Brasília: MEC, 1999.

Parecer CNE/CEB n. ${ }^{\circ}$ 38/2006. Inclusão obrigatória das disciplinas de Filosofia e Sociologia no currículo do Ensino Médio. Diário Oficial da União, Brasília, 14 de agosto de 2006.

Orientações curriculares para o Ensino Médio. Brasília, DF: MEC, 2006.

. Parecer CNE/CEB no 7, de 07 de abril de 2010. Apresenta Diretrizes Curriculares Nacionais Gerais para a Educação Básica. Diário Oficial da União, Brasília, 09 de julho de 2010.

Parecer CNE/CEB no 5, de 24 de janeiro de 2011. Apresenta Diretrizes Curriculares Nacionais para o Ensino Médio. Diário Oficial da União, 24 de janeiro de 2012.

Resolução CNE/CEB no 2, de 30 de janeiro de 2012. Define diretrizes curriculares nacionais para o ensino médio. Diário Oficial da União, Brasília, 31 de janeiro de 2012.

CARVALHO, José Murilo de. Cidadania no Brasil: o longo caminho. 10. ed. Rio de Janeiro: Civilização Brasileira, 2008. 
CASÃO, Carolina Dias Cunha; QUINTEIRO, Cristiane Thaís. Pensando a Sociologia no Ensino Médio através dos PCNEM e das OCNEM. Revista Mediações, v. 12, n. 1, p. 225 238, 2007.

CAVALCANTE, Maria do Socorro Aguiar de Oliveira. Qualidade e cidadania nas reformas da educação brasileira: o simulacro de um discurso modernizador. Maceió: Edufal, 2007.

CORTINA, Adela. Cidadãos do mundo: para uma teoria da cidadania. São Paulo, SP: Loyola, 2005 (Tradução de Silvana Cobucci Leite).

COUTINHO, Carlos. Nelson. 2008. Contra a corrente: ensaios sobre democracia e socialismo. 2. ed. rev. e atual. - São Paulo: Cortez.

DAGNINO, Evelina. Os movimentos sociais e a emergência de uma nova noção de cidadania. In: DAGNINO, Evelina (org.). Os anos 90: política e sociedade no Brasil. São Paulo: Brasiliense, 1994.

Confluência perversa, deslocamentos de sentido, crise discursiva. In: GRIMSON, Alejandro (org.). La cultura em las crisis latinoamericanas. Buenos Aires: CLACSO, 2004.

FLORÊNCIO, Ana Maria Gama et. al. Análise do discurso: fundamentos e práticas. Maceió: EDUFAL, 2009.

LÖWY, Michael. As aventuras de Karl Marx contra o Barão de Münchhausen: marxismo e positivismo na sociologia do conhecimento. 7. ed. São Paulo: Cortez, 2000.

MARSHALL, Thomas Humphrey. Cidadania, classe social e status. Rio de Janeiro: Zahar Editores, 1967.

MARX, Karl. Glosas críticas marginais ao artigo "O rei da Prússia e a reforma social": de um prussiano. São Paulo: Expressão Popular, 2010a (Tradução e introdução de Ivo Tonet).

Sobre a questão judaica. São Paulo: Boitempo, 2010b (Apresentação e posfácio de Daniel Bensaïd; tradução de Nélio Schneider, Daniel Bensaïd e Wanda Caldeira Brant).

MELO, Kátia. Discurso, consenso e conflito: a (re)significação da profissão docente no Brasil. Maceió: EDUFAL, 2011.

MÉSZÁROS, István. A educação para além do capital. 2. ed. ampliada. São Paulo: Boitempo, 2008 (Tradução de Isa Tavares).

MOEHLECKE, Sabrina. O ensino médio e as novas diretrizes curriculares nacionais: entre recorrências e novas inquietações. Rev. Bras. Educ., v.17, n.49, p.39-58. 2012.

MORAES, Amaury César. Ensino de Sociologia: periodização e campanha pela obrigatoriedade. Cadernos Cedes, Campinas, v. 31, n. 85, p. 359-382, 2011.

Ciência e ideologia na prática dos professores de sociologia no Ensino Médio: da neutralidade impossível ao engajamento indesejável, ou seria o inverso? Educação \& Realidade, Porto Alegre, v. 39, n. 1, p. 17-38, jan./mar. 2014. Disponível em: http://www.ufrgs.br/edu_realidade. Acesso em: 31 jan. 2014.

OLIVEIRA, Amurabi. O ensino de sociologia e as novas DCNEM. Educere et Educare, Cascavel - PR, vol. 9, n. 18, p. 641 - 650, jul.-dez. 2014. 
ORLANDI, Eni Pulcinelli. Análise de discurso: princípios e procedimentos. 2. ed. Campinas: Pontes, 2007.

As formas do silêncio: no movimento dos sentidos. 3. ed. Campinas - SP: Editora da UNICAMP, 1995.

PÊCHEUX, Michel. Semântica e discurso: uma crítica à afirmação do óbvio. 2. ed. Campinas, SP: Editora da UNICAMP, 1995 (Tradução de Eni Pulcinelli Orlandi et al.).

O discurso: estrutura ou acontecimento. 4. ed. Campinas, SP: Pontes Editores, 2006 (Tradução de Eni Pulcinelli Orlandi).

Papel da memória. In: ACHARD, Pierre et al. Papel da memória. Campinas SP: Pontes, 1999 (Tradução e introdução de José Horta)

.; FUCHS, Catherine. A propósito da Análise Automática do Discurso: atualização e perspectivas. In: Por uma Análise Automática do Discurso: uma introdução à obra de Michel Pêcheux. 3.ed. Campinas, SP: Editora da UNICAMP, 1997 (tradução de tradutores Bethania S. Mariani et al.).

RABELO, Jackline et. al. Educação para todos e reprodução do capital. Trabalho necessário, Rio de Janeiro, n. 9, ano 7, 2009. Disponível em:

http://www.uff.br/trabalhonecessario/images/TN09\%20JIMENEZ,\%20S.\%20et\%20al.pdf. Acesso em: 23 jan. 2015.

SAVIANI, Dermeval. A nova lei da educação: trajetória, limites e perspectivas. 11. ed. Campinas, SP: Autores Associados, 2008c.

SILVA SOBRINHO, Helson Flávio da. Manifestos, resoluções e o peso da lei: o discurso sobre a obrigatoriedade do ensino de Sociologia. In: OLIVEIRA, Dijaci David de et al. (org.). Ensino de Sociologia: currículo, metodologia e formação de professores. Goiânia:UFG/FUNAPE, 2011.

SOUZA, Davisson Charles Cangussu. O ensino de sociologia e a pedagogia históricocrítica: uma análise dos fundamentos teórico-metodológicos das propostas atuais. Revista HISTEDBR On-line, Campinas, nº 51, p. 122-138, jun. 2013.

TONET, Ivo. Educação, cidadania e emancipação humana. Ijuí: Unijuí, 2005.

Educação contra o capital. Maceió, Edufal, 2007.

UNESCO. Declaração Mundial sobre Educação Para Todos (Conferência de

Jomtien). Tailândia: Unesco, 1990. Disponível em:

<http://unesdoc.unesco.org/images/0008/000862/086291por.pdf>. Acesso em: 23 jan. 2015 .

WEBER, Max. A "Objetividade" do Conhecimento na Ciência Social e na Ciência Política. In: WEBER, Max. Metodologia das Ciências Sociais. 4. ed. São Paulo: Cortez, 2001 (parte 1). 


\section{Notas}

${ }^{1}$ Para uma abordagem acerca da evolução histórica da cidadania em suas dimensões civil, política e social, ver o trabalho "Cidadania, classe social e status" (MARSHALL, 1967). No que se refere ao Brasil, destacase a obra "Cidadania no Brasil: o longo caminho" (CARVALHO, 2008).

${ }^{2}$ De acordo com Orlandi (2007, p. 30-31), todo discurso se dá no interior de determinadas condições de produção discursivas, as quais, dizem respeito aos sujeitos envolvidos e a situação sócio-histórica e ideológica condicionadora.

${ }^{3}$ Conforme Pêcheux (1995, p. 160-161; PÊCHEUX; FUCHS, 1997, p. 168-169), a formação discursiva corresponde ao lugar sócio-histórico com o qual o sujeito-falante se identifica e, portanto, de onde enuncia. Essa identificação discursiva com um lugar historicamente determinado se dá mediante a atuação da ideologia, entendida como visão social de mundo, e, em última instância, define os "efeitos de sentidos" produzidos pelo sujeito-falante.

${ }^{4}$ É importante ressaltar que vários estudos já apontaram o caráter neoliberal da LDB e os diversos limites dos demais documentos que serão aqui analisados. No entanto, o presente estudo se justifica porque compreendemos que no tocante ao ensino de Sociologia os mesmos produzem - e convocam - efeitos de sentidos que ainda carecem ser melhor investigados.

5 Além da LDB 9.394/96, analisaremos neste trabalho os seguintes documentos: 1) Diretrizes Curriculares Nacionais para o Ensino Médio (DCNEM) de 1998 e de 2012); 2) Parâmetros Curriculares Nacionais para o Ensino Médio (PCNEM) de 1999; 3) Orientações Curriculares para o Ensino Médio, Conhecimentos de Sociologia (OCEM-Sociologia) de 2006.

${ }^{6}$ A partir de então passaremos a usar a sigla SD acrescida de um algarismo arábico para identificar a sequência discursiva à qual estaremos nos referindo.

${ }^{7}$ Intitulado Declaração Mundial sobre Educação para Todos: satisfação das necessidades básicas de aprendizagem, este documento sintetiza e impõe, em escala global, a adoção dos princípios e metas neoliberais no campo das políticas educacionais. Ele é resultado da Conferência Mundial sobre Educação Para Todos, realizada sob a liderança da Organização das Nações Unidas para a Educação, a Ciência e a Cultura (UNESCO), em Jomtien, na Tailândia, entre os dias 5 a 9 de março 1990 (RABELO et al., 2009; DIAS; LARA; 2008).

${ }^{8}$ Sobre a correlação de formas no processo de elaboração da LDB 9.394/96 ver Saviani (2008) e Araújo (1999).

${ }^{9}$ Segundo Orlandi (1995, p. 75), o dizer é inseparável do silenciamento, na medida em que “[...] ao dizer algo apagamos necessariamente outros sentidos possíveis, mas indesejáveis, em uma situação discursiva dada".

${ }^{10}$ Conforme nos lembra Cavalcante (2007, p. 90), “a naturalização não é o retorno à natureza, mas sim a consideração como natural aquilo que é histórico, produto do desenrolar histórico das relações sociais”.

${ }^{11}$ Lei $\mathrm{n}^{\circ} 12.061$, de 27 de outubro de 2009.

${ }^{12}$ Resolução CNE/CEB no 4 , de 13 de Julho de 2010.

${ }^{13}$ A autora refere-se ao ano de 2011 porque em seu texto analisa diretamente o Parecer CEB/CNE $n^{\circ} 5$, de 24 de janeiro de 2011, no interior do qual as DCNEM estavam inseridas ainda como proposta.

14 Emancipação humana é aqui entendida na esteira de Marx (2010a; 2010b), em contraposição a emancipação política, representada pela cidadania e pela democracia. Isto é, conforme Marx, embora a emancipação política represente uma conquista social que, inegavelmente, melhora as condições de vida e de luta dos trabalhadores, trata-se de uma emancipação formal, jurídico-política e, portanto, incapaz de superar as contradições e os limites da sociedade de classes. Já a emancipação humana, por sua vez, constitui a emancipação real, prática e, portanto, o horizonte societário pelo qual se deve lutar.

${ }^{15}$ Conforme Florêncio et al. (2009, p. 79), a memória discursiva corresponde “[...] ao lugar anterior, onde estão os já-ditos, prontos a serem convocados". Em outros termos: diz respeito ao lugar onde se encontra o interdiscurso que é retomado pelo dizer atual, mas que, como observam os autores, "não como uma repetição, mas como ressignificação". 
${ }^{16}$ Nos referimos aqui ao pensamento de Moraes e não somente ao texto em destaque porque o mesmo posicionamento já havia sido expresso em momentos anteriores, a exemplo de Moraes (2011, p. 365-367), bem como, em palestra proferida pelo autor no evento Semana de Ciências Sociais - E agora?: Sociologia pra quê: reflexões sobre a inserção da Sociologia no Ensino Médio, promovido pelo Instituto de Filosofia e Ciências Humanas (IFCH) da Universidade Estadual de Campinas (UNICAMP), entre os dias 01 e 04 de outubro de 2012. A participação de Amaury Cesar Moraes se deu no dia 03 de outubro, em uma mesa redonda em que dividiu a fala com a professora da Universidade Federal do Rio de Janeiro (UFRJ) Julia Polessa Maçaíra e com os estudantes da UNICAMP Amanda Villa Pereira, Juliana Closel Miraldi e Paulo Victor Albertoni Lisboa. O vídeo encontra-se disponível em: http://cameraweb.ccuec.unicamp.br/video/57711h7uww5m/\#sthash.AS3AOmyY.dpuf.

${ }^{17}$ Colocamos esta sentença entre aspas porque consideramos, a partir da $\mathrm{AD}$, que nenhum discurso se dá como expressão de uma subjetividade que tudo pode, uma vez que este constitui-se em "[...] índice potencial de uma agitação nas filiações sócio-históricas de identificação, na medida em que ele constitui ao mesmo tempo um efeito dessas filiações e um trabalho [...] de deslocamento no seu espaço" (PÊCHEUX, 2006, p. 56), o que, por sua vez, conforme esclarece Orlandi (2007, p. 35) "[...] não significa que não haja singularidade na maneira como a língua e a história nos afetam. Mas não somos o início delas”.

Recebido: abril-16 Aprovado: setembro-16 